\title{
Adenovirus-Encoding E.coli PNP
}

National Cancer Institute

\section{Source}

National Cancer Institute. Adenovirus-Encoding E.coli PNP. NCI Thesaurus. Code C96221.

A replication-incompetent adenovirus encoding E. coli purine nucleoside phosphorylase (Ad/PNP) used as a prodrug activating agent. Administered intratumorally, Ad/PNP expresses the enzyme PNP, which may catalyze systematically administrated fludarabine phosphate prodrug into its active form 2-fluoroadenine (F-Ade). F-Ade inhibits DNA polymerase alpha, ribonucleotide reductase and DNA primase, thereby interrupting DNA synthesis and inhibiting tumor cell growth. Localized prodrug activation provides targeted chemotherapy, thereby potentially reducing systemic side effects. 